\title{
Configuraciones subjetivas en la narrativa hispanoamericana: apuntes teóricos
}

\author{
Subjective configurations of hispanic narrative: \\ theoretical approach
}

\begin{abstract}
ANGÉLICA TORNERo
Universidad Autónoma del Estado de Morelos. Cuernavaca, México. atorneros@prodigy.net.mx

\section{RESUMEN}

En el presente ensayo se esboza teóricamente el problema de la configuración de la subjetividad en relación con textos literarios hispanoamericanos de mediados del siglo XX, específicamente de autores que decidieron alejarse de la estética realista. Se parte de la idea de que las configuraciones subjetivas ocurren como procedimientos complejos que pueden explicarse tanto desde la perspectiva de la identidad narrativa, de Paul Ricoeur, como a partir del enfoque del cuerpo-sujeto de Merleau-Ponty.
\end{abstract}

Palabras claves: Identidad, lector, texto, contexto, narrativa hispanoamericana.

\section{ABSTRACT}

In this article, the problem of the configuration of the subjectivity in $\mathrm{XX}^{\text {th }}$ Century Hispanic literary texts is outlined theoretically, specifically regarding authors who decided to move of the realistic aesthetic. The starting point of this reflection is the idea that subjective configurations take place as complex procedures that can be explained from Paul Ricouer's idea of narrative identity and from the approach of the body-subject of Merleau-Ponty.

Keywords: Identity, reader, text, context, hispanic narrative.

Recibido: 30-06-2009.

Aceptado: 04-09-2009. 


\section{INTRODUCCIÓN}

T a tendencia a reconsiderar críticamente la declaración de la "muerte del Lhombre" -atribuida a Michael Foucault (1988)- como sentencia definitiva que atraviesa nuestro mundo contemporáneo, se centra, en ocasiones, en la opción de hablar de nuevo del autor, de ese simulacro desacreditado hace ya algunas décadas por diversos críticos (Barthes, 1994: 65-71; Kristeva, 1981: 55-94) . Para ello, se acude con frecuencia a explorar la autobiografía, la relación del lector con el hablante o las ficcionalizaciones del yo que organiza la voz. Los aportes en este sentido son significativos y han arrojado interesantes perspectivas sobre el tema (Pozuelo, 2005; Molloy, 1996; Romera, 1993).

Esta inclinación por explorar los límites y posibilidades del sujeto que dice algo sobre el mundo, abre interesantes perspectivas para reconsiderar un posible enfoque teórico interesado en pensar en la identidad del personaje literario, más allá de las perspectivas formales. En el marco de estas consideraciones, en este artículo reflexiono sobre la cuestión a partir de elementos estructurales, así como de hermenéutica. El objetivo es describir el proceso de comprensión de la subjetividad por parte del lector, en relación con la configuración de la identidad de los personajes. Parto de la idea que el personaje y el lector se configuran mutuamente como mundos posibles. El sujeto no es ya la condición del mundo sino la interacción operada a manera de interfaz.

Dos autores sirven de marco teórico y referencial para llevar a cabo esta reflexión. Por una parte, retomo las consideraciones realizadas por Paul Ricoeur sobre el tema de la identidad narrativa; por otra, recupero la idea de cuerposujeto de Maurice Merleau-Ponty. Esta meditación tiene como base empírica el análisis de algunos textos literarios hispanoamericanos, escritos a mediados del siglo XX, que abiertamente se alejan de la estética realista.

\section{DE QUÉ SUJETO SE HABLA}

La idea moderna de sujeto surge como principio crítico en contra del dogmatismo religioso, prevaleciente durante la Edad media. Esta nueva concepción ubica al sujeto en un lugar privilegiado, a partir del cual se legitima todo valor. Este se vuelve central y desplaza a Dios como fundamento, como fuente originaria. Este movimiento del centro de gravedad conduce a la modificación de las relaciones sociales y políticas y a la secularización en los países europeos.

La concepción moderna de sujeto fue formulada por primera vez por Descartes, no obstante, su desarrollo no sigue una línea homogénea, lo que hace 
de la exploración de esta idea una tarea ardua. No intentaré aquí hacer una relación de las diferentes aproximaciones a la problemática del sujeto. Para contextualizar la concepción de sujeto del que se habla, he elegido exponer dos enfoques: el que da origen a esta concepción en la época moderna, la filosofía de Descartes, y una de las propuestas de rechazo a esta idea, a partir de la crítica de Heidegger.

En sus meditaciones, Descartes señala que su método lo condujo a la duda, por lo que se propuso indagar si acaso hay algo sobre lo que se puede tener certeza (1998: 46-47). Así, la pregunta que motiva el desarrollo filosófico de Descartes es si es posible afirmar algo; es decir, bajo qué condiciones se legitima afirmar que algo es algo. De aquello que se puede afirmar algo indubitablemente es del yo pienso, porque de todo lo demás se debe dudar $(50$ y ss). Lo único cierto de lo que pienso es que yo lo pienso. Es en el yo pienso, en la mente, en donde tiene lugar la legitimidad. Para Descartes, el sujeto no es el de un enunciado, sino que está ya de antemano en todo, porque es un sujeto del enunciado como tal. Es decir, Descartes se refiere a la mente, al yo pienso y no sólo al sujeto de un enunciado particular. El sujeto es fundamento. En la obra de este filósofo se observa también la idea de sujeto como actividad. En el sujeto se origina la actividad que es expresión del yo. La idea es retomada por filósofos posteriores, con diferentes desarrollos. Una de las propuestas más importantes, en este sentido, fue la de Kant. En el acto de conocimiento, el sujeto cognoscente modifica la realidad conocida; es decir, el sujeto procesa la realidad de acuerdo con sus posibilidades. En cuanto ser pensante, el sujeto se convierte en absoluto de todos los juicios posibles (Kant, 2005).

Esta idea del sujeto central, fuerte y constitutivo de los objetos, ha sido motivo de numerosos debates, que sería imposible mencionar aquí. Destacaré uno de los más importantes, que ilustra una postura en contra de la concepción de sujeto de Descartes, me refiero al debate iniciado por Heidegger. El filósofo contribuyó a poner en cuestión la idea moderna de sujeto, que fue enaltecida por la Ilustración y que ha sido criticada severamente por el posestructuralismo francés y la posmodernidad. En las primeras páginas de Ser y tiempo (1951: $11)^{1}$. Heidegger señala de manera crítica el olvido del ser en toda la metafísica occidental. Es decir, la primacía del pensamiento sobre el ente en detrimento del ser del ente. En la base de este señalamiento medular, se advierte la crítica que hace Heidegger a la distinción moderna sujeto-objeto. La pregunta que se hace el filósofo es si la conciencia pura es nuestro a prior o si existe una estructu-

\footnotetext{
${ }^{1}$ Heidegger modificó su pensamiento en obras ulteriores. Me limito aquí a los planteamientos desarrollados en Ser y tiempo.
} 
ra previa a partir de la cual adquiere sentido la primacía de la conciencia. Dicho de otro modo, se pregunta si a la conciencia le antecede una estructura que no ha sido considerada y que es precisamente lo que permite otorgarle este sitio privilegiado. Esta interrogante conduce a Heidegger a buscar otra respuesta distinta de la que ha dado la filosofía que le antecede. Para él, el hombre no es un sujeto; es aquel que está en relación con el ser y se pregunta por su sentido. Es decir, el modo de ser del hombre es que se interroga por el ser (35). Con la noción de Dasein, que puede ser entendida como la apertura del ente que es el hombre al ser, Heidegger propone el descentramiento. El Dasein, a diferencia del sujeto, implica descentramiento, porque se trata del ente que está ahí donde el ser se aclara en su sentido (53 y ss). Otro aspecto importante de la filosofía de Heidegger es haber mostrado que el Dasein está referido al mundo como totalidad y es desde su ser-en-el-mundo que se relaciona con otros entes e incluso consigo mismo (66 y ss). De aquí se deriva la idea de que no hay un sujeto que se tenga a sí mismo de manera inmediata, original, sino que resulta de una interpretación.

Esta discusión de Heidegger con la idea moderna de sujeto tiene múltiples más aristas que es imposible exponer aquí. Baste decir que la puesta en cuestionamiento de ese sujeto central consistió para el filósofo en criticar el valor que la filosofía moderna le otorgó a la racionalidad, en términos de procedimiento intelectual que utiliza conceptos para determinar el objeto de pensamiento. Sirvan estas dos perspectivas, la que crea esta concepción de sujeto, es decir, la cartesiana y la que intenta terminar con ella, la heideggeriana para comprender, en una mirada rápida, de qué sujeto se habla.

\section{CONFIGURACIONES SUBJETIVAS}

Para desarrollar estas reflexiones retomé, por una parte, la noción de interfaz, que proviene de la cibernética y que en el campo de la teoría literaria y la hermenéutica fue trabajada por Wolfgang Iser (2006); por otra parte, consideré la idea de cuerpo-sujeto y su relación con el lenguaje, de Merleau-Ponty y la hermenéutica de Paul Ricoeur, sobre todo vinculada con el asunto de la identidad narrativa. Antes de desarrollar las reflexiones personales sobre el tema, expondré brevemente las ideas retomadas de estas consideraciones teóricas.

\subsection{CUERPO-SUJETO E IDENTIDAD NARRATIVA}

Las aportaciones de Merleau-Ponty a la discusión sobre el sujeto han sido reto- 
madas por distintos pensadores para encontrar un sustento a la epistemología o, mejor dicho, a las ciencias cognitivas actuales. Su enfoque goza hoy de prestigio en estos ámbitos del conocimiento. Este filósofo considera al sujeto como un cuerpo-sujeto que introduce la anomalía de lo verdaderamente humano y muestra la virtud de lo ambiguo. El cuerpo no es sólo sujeto ni sólo objeto; es cuerpo fenoménico, forma de ser vivencial, carnal (Merleau-Ponty, 1970). ${ }^{2}$ Para el filósofo, el cuerpo propio es condición de nuestra situación, y media entre lo externo y lo interno. Es, además, base del cuerpo vivido y es inseparable del mundo y de sus relaciones con otros. El cuerpo no es un ser objetivo, una realidad física, sino algo que soy. El cuerpo es cuerpo vivido y la conciencia es alma encarnada. Los objetos de esta conciencia son núcleos de significación experimentados en virtud de la aprehensión precognitiva de la unidad de nuestro cuerpo (1975).

Para Merleau-Ponty el lenguaje es el campo por excelencia de los entrecruzamientos; es el lugar en el que la corporalidad sensible y la espiritualidad pura superan su separación, se encuentran y articulan (Ramírez, 1994: 151), lo cual no significa que sean idénticos. El cuerpo que siente es también un cuerpo que habla y que piensa, que comprende y que posee una memoria histórica y forma parte y actúa en una sociedad. Es decir, el autor describe el movimiento del ser humano del mundo del cuerpo, al lenguaje y al pensamiento, a partir de relaciones de superposición. Especialmente relevante es el lenguaje literario para el autor. Este lenguaje $-y$ en general, las expresiones artísticas- plantean una nueva vinculación entre el ser humano y el mundo. Según Merleau-Ponty, el lenguaje literario refiere el reverso invisible de las cosas y dice su indecible silencio. Pero esto no es un impedimento para el filósofo, sino por el contrario, es una oportunidad de experimentar el ser del lenguaje con su verdadera fuerza. El lenguaje configurado de este modo, que será el caso de la literatura contemporánea, permitirá experimentar con mayor profundidad la vida humana.

Otro autor relevante en este sentido es Paul Ricoeur. El filósofo describe la idea de la identidad narrativa, en el marco de la hermenéutica del sí, con el objetivo de desarrollar un planteamiento ético. En esta propuesta conjuntó los niveles precedentes de su descripción: discurso, acción y narración, y los vinculó con las dimensiones éticas del sujeto susceptible de imputación. El sí narrante y narrado desempeñan, en la hermenéutica del filósofo, el rol de cruce entre la teoría de la acción y la teoría moral (1997: 82). La hermenéutica del sí mismo consiste en dejarse atravesar por todos los textos de la cultura. Una

2 "Mi cuerpo modelo de las cosas y las cosas modelo de mi cuerpo: el cuerpo atado por todas partes al mundo, pegado a él; todo eso significa: el mundo, la carne, no como hecho sino como suma de hechos, sino como lugar de una inscripción de verdad" (Merleau-Ponty, 1970: 164). 
vida examinada, dice Ricoeur, es en gran parte una vida depurada, clarificada, por los efectos catárticos de los relatos. La ipseidad es, así, la de un sí mismo instruido por las obras de la cultura que él se aplicó a sí mismo (Ricoeur, 1996). Esta ipseidad conduce de una hermenéutica a una ética, ya que la propia intriga permite al lector hacer evaluaciones sobre las acciones que configuran la identidad narrativa.

Para Ricoeur, la identidad narrativa deja atrás la comprensión de la identidad personal como idem, es decir, como idéntica, para alcanzar la identidad del sí-mismo o ipse, que reconoce una identidad cambiante en la cohesión de una vida (1996: 998). Así, el sujeto aparece constituido a la vez como lector y como escritor de su propia vida, como lo deseaba Proust. El lector es también escritor, porque al refigurar hace de la propia vida un tejido de historias narradas, que lo conducen hacia su sí mismo.

\subsection{EL SUJETO: UNA INTERFAZ}

El concepto de interfaz se refiere en términos generales a la superficie de contacto o simplemente a la superficie a lo largo de la cual convergen dos cosas de naturaleza distinta. Este término es original del inglés y el diccionario Webster ofrece diversos significados. Se entiende por interfaz la superficie considerada como el límite común entre dos cuerpos o espacios. También se dice de este término que se refiere a los hechos o problemas, consideraciones teóricas, prácticas, etc., compartidas por dos o más disciplinas, procedimientos o campos de estudio. En las ciencias de la computación la noción señala aquello que, a la vez, conforma el límite y el espacio común que hay entre el hombre y el ordenador o computadora (Catàla, 2001).

Esta noción ha sido trasladada metafóricamente a ámbitos de estudios interdisciplinarios: ciencias cognitivas, por ejemplo, que incluyen perspectivas desde la lingüística, la antropología, la filosofía. El mismo Wolfgang Iser, en uno de sus últimos trabajos, How to do theory (2006), se refiere a su propuesta en estos términos:

Desde mi perspectiva este traslado es pertinente en los estudios literarios con vocación interdisciplinaria, no sólo porque ofrece posibilidades de comprender de manera ampliada la interacción del lector y el texto, sino porque la interfaz se puede entender como algo más que un aditamento electrónico o una tecnología; una sintaxis visual o verbal o los niveles de lengua. La interfaz es el espacio virtual que une al lector con el texto a partir de operaciones activadas en ambos polos. La interfaz, así entendida, es el propio yo que se organiza como virtualidad, al tiempo que activa o desencadena operaciones interpretativas en 
la "región", si se permite la metáfora espacial, de la imaginación. Es decir, el yo es una virtualidad que se organiza en relación con el texto como práctica hermenéutica, disuelto en una compleja red de particularidades que implican al lector, al texto y al contexto, y a la vez, distinguiéndose del mundo del texto -acciones y personajes- a partir del logro de su coherencia interna. Con esto quiero decir que, en relación con el texto literario, no hay un yo anterior a la práctica hermenéutica y su actuar en la región de la imaginación, sino que es esta misma su historia y su actuar.

Esta comprensión de la interfaz implica que el yo que lee no se aproxima al texto literario como un ente pasivo observador de las cosas que suceden en la novela, sino que interactúa, desde luego, de manera diferente. En un interesante estudio sobre la interfaz en la tecnología, Josep Catàla (2001) apunta que ésta pone al descubierto el modelo mental actual, como lo hicieran en su momento la dramaturgia que tenía como escenario el Epidauro y la cámara oscura. Entonces, se trataba de sujetos frente a objetos, contemplativos. La interfaz pone en evidencia una manifestación epistemológica diferente: permite convertir la identificación en una función activa constante y, a la vez, genera la operación contraria: diluir la irracionalidad de este momento catártico en el ámbito de la visibilidad metafórica que es de carácter espacial.

El arte en general y específicamente las novelas -y la poesía- escritas a lo largo del siglo XX, y sobre todo la narrativa llamada experimental, dan cuenta también de ésta que, me parece, debe considerarse como algo más que epistemología y algo más que ontología, o, en todo caso, como el movimiento simultáneo de ambas. Si el lector o el usuario del ordenador se distinguen y encuentran su coherencia al mismo tiempo, al interactuar mediante la interfaz, y si este proceso de interactuación implica temporalidad y situación y también virtualidad y posibilidad, entonces se está hablando de una amalgama entre el sujeto y el objeto, de la que resulta muy complejo distinguir fronteras, sobre todo al observador externo.

\subsection{EL YO-INTERFAZ EN TRES REGISTROS}

En los siguientes párrafos reflexionaré sobre los constitutivos de las configuraciones subjetivas de la relación entre el lector con algunos textos de la literatura hispanoamericana, específicamente de mediados del siglo XX, que intentaron alejarse de la estética realista.

Como mencioné arriba, entiendo al yo como gozne que articula al texto con el lector; es decir, como interfaz. La interfaz se describe, en primer término, como movimiento articulatorio de la complejidad de operaciones que realizan 
el lector y el texto, los cuales, al entrar en contacto, se actualizan mutuamente en relación con el contexto. Esta interfaz, en el marco de la literatura contemporánea, no es otra cosa que el propio yo que autoorganiza su comprensión en tres registros: el primero, es el de las acciones simbólicas a partir de la idea de identidad narrativa; el segundo, el de señales en tanto operaciones de estimulación simbólico-sensocorporal, no entendidas como señales institucionalizadas, sino, al contrario, como aquellas que intentan romper la institucionalidad, que permiten la configuración de la subjetividad más en términos de cuerpo-sujeto que de identidad narrativa, y el tercero, el contexto, en el cual estos dos se actualizan a través de operaciones recursivas de interpretación.

En cuanto al primer registro, la identidad narrativa, me parece que, si bien está presente en esta literatura, es el caso paradigmático de García Márquez, incluso, a su modo Rulfo, en ciertas obras Borges y en otras más Vargas Llosa, sólo por mencionar algunos, no parece ser el componente principal de la subjetividad ni de personajes ni de lectores. En el nivel de la historia, varias de las novelas de estos autores narran acontecimientos a la usanza del realismo. Estos acontecimientos están constituidos por los destinos de los personajes y por conflictos de tipo histórico, político, económico. No obstante, esta obras no exponen la realidad, ni lo pretenden, de manera directa, sino superponiendo mundos. Además, los personajes no son identidades configuradas convencionalmente, digamos a la manera de las narraciones orales, sino procesos de expresión de pérdida de identidad. Así, la identidad de los personajes resulta como configuración de acciones inestables, frente a las cuales el lector no puede fácilmente cerrar el sentido de la vida del personaje.

Es decir, en estos textos, la identidad narrativa no provee al lector la posibilidad del sentido, a partir de la dialéctica entre acontecimientos imprevisibles y su carácter de necesidad al ser vistos retroactivamente en el marco de la historia de una vida ${ }^{3}$, porque estas vidas aparecen, en muchos casos desarticuladas, precisamente por la inserción de otros mundos posibles. Estos textos se acercan a lo que Ricoeur observó en relación con la narrativa que pone a prueba la noción de trama que él sostiene. Se trata de indecidibles (Parfit citado por Ricoeur, 1996: 170). El filósofo francés afirma que este tipo de narrativas sugieren una dialéctica de la posesión y el desposeimiento. Aquí, la nada imaginada del sí se transforma en crisis existencial del sí, lo cual no hace necesario que esta crisis sustituya la estima del sí por el odio del sí (172). A propósito de la discordancia

\footnotetext{
${ }^{3}$ Paul Ricoeur dice al respecto: "[...] estos casos desconcertantes de la narratividad [...] constituyen el polo opuesto del héroe identificable por superposición de la ipseidad y de la mismidad. Lo que ahora se pierde en términos de 'atributo' es lo que permitiría igualar al personaje con su carácter" (1996: 149).
} 
concordante que el filósofo observa en la construcción de las tramas, afirma que al leer estas novelas el lector podrá experimentar con una mayor profundidad la manera de comprender el orden de la vida humana en toda su amplitud. La configuración puede sugerir el cierre o no cierre de la novela, pero el lector espera algo, está a la expectativa de la concordancia; espera una señal para cooperar en la obra, "para que cree él mismo la trama" (Ricoeur, 1996: 412).

Los textos hispanoamericanos de esta época, me parece, lograron crear una propuesta limítrofe entre configuraciones subjetivas como identidades narrativas y estas mismas como intento de suspensión de la narración para evidenciar al cuerpo-sujeto como co-productor del sentido, pero no desde la positividad.

El segundo registro, precisamente el cuerpo-sujeto, destaca en la mayor parte de las novelas de esta época. El lenguaje, en este caso, se manifiesta en su ambigüedad fundamental y replantea la relación entre lenguaje y realidad para encontrar una nueva vinculación entre el ser humano y el mundo. Estos textos resquebrajan el planteamiento de un ser unívoco, eterno, visible, y proponen una realidad inaprehensible emanada del vacío. Estos autores piensan el lenguaje como un entramado unificado de relaciones concordantes, pero que es incapaz de presentar el sentido en su positividad (Bech: 223).

En general, los personajes de la literatura del siglo XX no responden a la pregunta ¿quién soy en verdad? Algunas obras de este siglo, como es bien sabido, se dieron a la tarea de anular esta pregunta con la negación, es decir, con la construcción de propuestas que negaran toda posibilidad de pensar en la identidad, como el caso de la nouveau roman (Ricardou, 1973). No es exactamente ésta la propuesta de la literatura hispanoamericana aludida, pero tampoco en estos textos se configuran personajes que respondan a aquella pregunta y mucho menos lectores que exijan respuesta a ella. Lo que se expresa en esta literatura como subjetividad de los personajes es lo que éstos hacen, en términos de acciones narradas, insertadas en determinadas prácticas simbólicas o de ejercicios de suspensión de la narración, que intentan interrumpir el sentido, con lo que crean sentidos alternativos, resueltos por el lector en el plano de la imaginación que es parte del proceso de configuración misma de esta subjetividad.

En los textos hispanoamericanos de los autores mencionados, y otros de esta época, la contingencia no sólo está dada por las acciones que realizan los personajes y que el lector hace suyas, en tanto sentido de su propio carácter contingente, sino también por lo que supone experimentar el umbral, ser yo en tanto umbral. En este sentido, las acciones de los personajes no son ya significativas en un marco de coherencia dada por prácticas localistas, sino por la difusión de esas particularidades, no en lo global, en lo hiperespacial, entendido como el espacio de realización de otros mundos posibles en el mismo mundo. Los 
personajes posrealistas del mal llamado realismo mágico ${ }^{4}$ o mundo fantástico o fantasía, son personajes limítrofes, sujetos de acciones y prácticas difíciles de discernir en un marco interpretativo convencional, no por estar localizados en un ámbito geocultural exótico o mágico, sino por configurarse entre mundos y propiciar otra experiencia de intercorporeidad (Merleau-Ponty, 1975) y por lo tanto de espacio-tiempo.

El tercer registro mencionado se refiere al contexto. Sobre éste sólo diré que es la configuración misma de la interfaz. Es decir, el contexto es el movimiento del lector hacia el texto y viceversa, con todo lo que implica: desde la activación física de las particularidades hasta la constitución de la subjetividad, como experiencia de expresar el yo, en el campo sociocultural y por tanto simbólico. Se considera aquí que el contexto es el movimiento recursivo de la interpretación y que tiende a anular la idea del sujeto dualista que se comprende como interioridad y/o como exterioridad.

Termino con dos ejemplificaciones. "Las babas del diablo", de Julio Cortázar, inicia con una reflexión sobre las posibilidades de transmitir, no necesariamente narrar, una experiencia. Los problemas aludidos en los primeros párrafos se relacionan con el cuestionamiento en torno de las posibilidades del lenguaje. El lenguaje limita, impide, circunscribe, ¿cómo expresar al ser en tanto experiencia?, parece preguntarse el escritor. La respuesta que ofrece en este cuento es la construcción de diferentes subjetividades, pero no en términos de responder a la pregunta quién es, sino sobre todo, qué hace y cómo lo hace.

Los yoes de este cuento son desplazamientos del propio yo por otras dimensiones, infancia, vida adulta y muerte; es decir por otros espacio-tiempos, no por otros tiempos solamente, en términos de pasado, presente o futuro. En este cuento, la interfaz se resuelve sobre todo como cuerpo-sujeto, porque la narración tiende a disiparse, por un lado, en aras de la suspensión del tiempo y, por otro, de la configuración de otras dimensiones. Uno de los pasajes clave en el cuento que permite entender la intención es el siguiente: "Ya sé que lo más difícil va a ser la manera de contarlo, y no tengo miedo de repetirme. Va a ser difícil porque nadie sabe quién es el que verdaderamente está contando, si soy yo o eso que ha ocurrido, o lo que estoy viendo..." (Cortázar, 2004: 125). Me parece que la idea fundamental de la configuración de la subjetividad en ese cuento es nadie narra, se narran los sucesos, los cuales, agrego, configuran la subjetividad del yo, producen yoes.

En El tornavoz (2004), de Jesús Gardea, se simula una historia a partir de la

\footnotetext{
${ }^{4} \mathrm{Al}$ decir "mal llamado" manifiesto mi desacuerdo con esta denominación e incluso caracterización. Este no es el espacio para extenderme en la explicación de este asunto.
} 
estructura de personajes sucesivos, que forman parte de una familia, los Paniagua. Si se tomara en cuenta la edad de los diferentes personajes, con el supuesto de que se narra la saga de tres generaciones, se podría concluir que en esta novela se abarca alrededor de cien años, a semejanza de la famosa novela de García Márquez. Hay, no obstante, elementos que permiten pensar que no es así. En la novela se narra cómo Cándido Paniagua se introduce en el mundo de los vivos y cómo los vivos reciben a este muerto. La temporalidad judeocristiana perfilada por el linaje, aquí, es sólo una tentativa; este tiempo no se cumple. Prevalece el tiempo mítico que imbrica dos espacio-temporalidades: la de los vivos y la de los muertos. Esta imbricación ocurre a partir de una estrategia de deconstrucción que provoca la polisemia en los polos de la dicotomía. La distinción vivo/ muerto se desestructura y los valores de uno y otro pierden su lugar, definido dentro de la simbólica del catolicismo, desestabilizando el sentido. ¿Son los vivos los muertos? Los vivos y los muertos comparten características y unos son comprendidos a partir de los otros.

La configuración de las subjetividades de los personajes descansa en la interfaz como producción del cuerpo-sujeto, que advierte, sobre todo, la ambigüedad de la existencia humana, dada por este mundo simultáneo de muertos y vivos, que tiene como intención expresar la soledad. En Placeres no ocurre nada; todos son intentos fallidos de comunicarse, lo que hace que la identidad se disipe.

\section{CONSIDERACIONES FINALES}

La narrativa de esa época no parece haber discutido la afirmación de la identidad localista, como se ha dicho en reiteradas ocasiones, sino más bien la producción de yoes-mundos alternativos, tanto a su propia realidad como a la de sus referentes inmediatos, Europa y Estados Unidos. Si bien los autores retoman sus circunstancias, los rasgos específicos de éstas no son determinantes para la construcción de una identidad constitutiva o constituyente ni para una comprensión de sí.

Lo que en este artículo se desarrolló es la idea que surge de los planteamientos mismos de esta narrativa: el sujeto como interfaz. Es decir, no se trata ya de pensar a un sujeto que constituye, que adecua, pero tampoco de un no sujeto, por el hecho de que estas narrativas pretenden borrar al quien que habla, sino de una interfaz que permite la unión entre los mundos posibles: el del texto y el del lector. El yo será, así, una virtualidad, un espacio entre, que se activa en el momento de la lectura. 
Como se vio, se ha pensado en dos formas de realización de este yo como virtualidad. Por un lado, a partir de la identidad narrativa, en el sentido de Paul Ricoeur. El yo realiza operaciones que conducen a la comprensión simbólicamente del contexto. Por otro lado, a partir del concepto de cuerpo-sujeto de Merleau-Ponty, se puede pensar que el uso del lenguaje, la expresión, en palabras del filósofo, pretende llevar a las frases a una vida relativa y variable, que conduce al lector a la ambigüedad. No obstante, esto no significa que no haya sentido, pero no provendrá desde la positividad. Es decir, en estas narrativas, podemos observar la co-existencia de estas dos formas de configuración y, por lo tanto, de dos maneras de refiguración.

El lector se topa, así, con relatos en los que, por una parte, se encadenan sucesos, pero, por otra, se configuran formas del lenguaje, expresiones y construcciones complejas, a partir de juegos con el espaciotiempo, que desestabilizan el sentido, porque destacan ausencia más que presencia y negatividad más que positividad. Esto crea una tensión entre dos formas de configurar la subjetividad que, desde mi perspectiva, enriquecen de manera ostensible al lector.

En este artículo se esbozaron apenas algunos elementos que pueden contribuir a realizar otra lectura más de la constitución de la subjetividad en los textos narrativos hispanoamericanos.

\section{REFERENCIAS}

Barthes, R. 1994. El susurro del lenguaje. Más allá de la palabra y de la escritura. Buenos Aires: Paidós.

Bech, J. M. 2005. Merleau-Ponty. Una aproximación a su pensamiento. Barcelona: Anthropos.

Catàla, J. 2001. "La rebelión de la mirada. Introducción a una fenomenología de la interfaz", en Format. Revista de comunicación audiovisual 3. [En línea] Disponible en: http://www.wikilearning.com/monografia/la_rebelion_de_la_mirada_introduccion_a_una_fenomenologia_de_la_interfazla_rebelion_de_la_mirada_introduccion_a_una_fenomenologia/6886-1. Consulta: 06/11/2009.

Cortázar, J. 2004. Las armas secretas. Madrid: Cátedra.

Descartes, R. 1998. El discurso del método. México: Losada.

Foucault, M. 1988. Las palabras y las cosas. México: Siglo XXI.

Gardea, J. 2004. El tornavoz. México: Ediciones sin Nombre/Consejo Nacional para Cultura y las Artes.

Heidegger, M. 1951. Ser y tiempo. México: Fondo de Cultura Económica. 
Iser, Wolfgang. 2006. How to do theory. Londres: Blackwell Publishing Ltd. Kant. E. 2005. Crítica de la razón pura. Madrid: Taurus.

Kristeva. J. 1981. "Poesía y negatividad", en Semiótica 2, pp. 55-94.

Merleau-Ponty, M. 1970. Lo visible y lo invisible. Barcelona: Seix Barral.

Merleau-Ponty, M. 1975. Fenomenología de la percepción. Barcelona: Península.

Molloy, S. 1996. Acto de presencia. La escritura autobiográfica en Hispanoamérica. México: El Colegio de México/FCE.

Pozuelo Yvancos, J. M. 2005. De la autobiografía: Teoría y estilos. Madrid: Editorial Crítica.

Ramírez, M. T. 1994. El quiasmo. Ensayo sobre la filosofía de Maurice MerleauPonty. México: Universidad Michoacana.

Ricardou, J. 1973. Le nouveau roman. París: Seuil.

Ricoeur, P. 1996. Sí mismo como otro. Madrid: Siglo XXI de España Editores/ Siglo XXI Editores.

Ricoeur, P. 1997. Autobiografía intelectual. Buenos Aires: Nueva Visión.

Romera, J. 1993. Escritura autobiográfica. Madrid: Visor-Libros. 